\title{
Anti-carburizing Coating for Resin Sand Casting of Low Carbon Steel Based on Composite Silicate Powder Containing Zirconium
}

\author{
Chunyi Zhan ${ }^{1,2}$, Shengshan Feng ${ }^{1,2^{*}}$, Shuzhong Xie ${ }^{3,4}$, Chunjing Liu ${ }^{3,4}$, \\ Yunhua Gao ${ }^{3,4}$, and Jiahao Liang ${ }^{3,4}$ \\ ${ }^{1}$ College of Mechanical and Electrical Engineering, Guangdong Polytechnic of Science and \\ Technology, Zhuhai 519090, China \\ ${ }^{2}$ Zhuhai Key Laboratory of Advanced Equipment Manufacturing and Material Processing Technology, \\ Zhuhai 519090, China \\ ${ }^{3}$ Zhuhai Doumen Fulian Molding Materials Industry Co., Ltd, Zhuhai 519080, China \\ ${ }^{4}$ Guangdong Molding Material Engineering Technology Center, Zhuhai 519080, China
}

\begin{abstract}
This paper studied the structure and properties of anticarburizing coating based on composite silicate powder containing zirconium by X-ray diffraction analyzer, thermal expansion tester, digital microscope and other equipment. It is introduced that the application example of the coating in the resin-sand casting of ZG1Cr18Ni9Ti stainless steel impeller. The anti-carburizing effect of the coating on the surface layer of the cast is studied by using direct reading spectrometer and spectrum analyzer. The change of the micro-structure of the coating after casting and cooling is observed by scanning electron microscope. The analysis of anti-carburizing mechanism of the coating is presented. The results indicate that the coating possesses excellent suspension property, brush ability, permeability, levelling property and crackresistance. The coating exhibits high strength and low gas evolution. Most of the coating could be automatically stripped off flakily when the casting was shaken out. The casting possesses excellent surface finish and antimetal penetration effect. The carburizing layer thickness of the stainless steel impeller casting with respect to allowable upper limit of carbon content is about $1 \mathrm{~mm}$ and maximum carburizing rate is $23.6 \%$. The anticarburizing effect of casting surface is greatly improved than that of zircon powder coating whose maximum carburizing rate is $67.9 \%$ and the carburizing layer thickness with respect to allowable upper limit of carbon content is greater than $2 \mathrm{~mm}$. The composite silicate powder containing zirconium coating substantially reduces the zircon powder which is expensive and radioactive and mainly dependent on imports. The coating can be used instead of pure zircon powder coating to effectively prevent metal-penetration and carburizing of resin-sand-casting surface of low carbon steel, significantly improve the foundry production environment and reduce the production costs.
\end{abstract}

* Corresponding author: fss8172@126.com 


\section{Introduction}

Resin sand process is one of the main methods for producing carbon steel castings. However, it is easy to cause carburization defects in the surface of low carbon steels. The pearlite increases, ferrite decreases and acicular martensite appear in its microstructure, which leads to the decrease of plasticity, toughness, machining and welding performance [1-5]. To solve these problems, it is necessary to form a coating with a certain thickness of dense sintering layer on the surface of resin sand mold (core) under high temperature. Meanwhile, adhering sand and carburizing of casting surface are avoided.

Zircon powder is now widely used as a refractory material for anti-carburizing and antisand burning coating for low-carbon steel cast at home and abroad [4-6]. But its mineral is scarce and expensive. Moreover, monazite contains low concentrations of uranium and thorium oxides, it has a certain intensity of radioactivity and can produce ionizing radiation, which can cause excitation and ionization of biological macromolecules, cause DNA damage and increase chromosome aberration rate [6, 7]. Therefore, it is imminent to study and search for substitute materials of zircon powder.

In this paper, low-cost composite silicate powder refractory material containing zirconium is used to develop new coatings for steel castings, which has weak or no radioactivity, lower cost of production, which can be automatically peeled off, and has a good effect on both on anti-carburizing and anti-metal-penetration. It can meet the urgent needs of low carbon steel casting, which has low production cost, high quality and environmental friendliness.

\section{Composition design of composite silicate powder anti- carburizing coating containing zirconium}

Foundry coating is commonly composed of refractory aggregate, binder, sintering agent, suspending agent, solvent, assistant and other components.

\subsection{Refractory aggregate}

Refractory aggregate is the skeleton of foundry coating. It should have high temperature and heat resistance in order to avoid the formation of mechanical sand castings, and also should have stable chemical property at high temperature in order to avoid interfacial chemical reaction with sand mold or core and molten metal.

In this experiment, composite silicate powder containing zirconium was selected as the main refractory aggregate. It is an aluminum silicate based composite silicate with milky white color, whose chemical is as follows: $\mathrm{Al}_{2} \mathrm{O}_{3} \geqslant 50 \%, \mathrm{SiO}_{2} \leqslant 35 \%, \mathrm{Fe}_{2} \mathrm{O}_{3} \leqslant$ $1 \%, \mathrm{TiO}_{2} \leqslant 5 \%, \mathrm{ZrO}_{2} \leqslant 9 \%$.

According to the test results of specific activity of radionuclide of composite silicate powder containing zirconium show that, the specific activity of $U$ is $1.671 \mathrm{~Bq} / \mathrm{g}$ and $\mathrm{Th}$ is $0.413 \mathrm{~Bq} / \mathrm{g}$, about half the specific activity of radionuclide in Australia and South Africa (U $2.0 \mathrm{~Bq} / \mathrm{g} \sim 4.0 \mathrm{~Bq} / \mathrm{g}$, Th $0.1 \mathrm{~Bq} / \mathrm{g} \sim 1.0 \mathrm{~Bq} / \mathrm{g}$ ). It has good safety and environment-friendly.

The $\mathrm{X}$ ray diffraction petrographic analysis map of the composite silicate powder containing zirconium is shown in Fig. 1. XRD analysis results show that the lithofacies of the composite silicate powder containing zirconium is mainly corundum, quartz, zirconite and kyanite.

The coefficient of linear expansion of the kyanite in the composite silicate powder containing zirconium in the heating process is high. When heated to about 1100 degrees celsius, it begins to decompose into mullite and ristobalite (glass polymer) and 
volume dilation occurs at the same time. When heated to over 1300 degrees celsius, it decomposes rapidly. When heated to over 1450 degrees celsius, it decomposes completely in the main and totally transform into mullite and ristobalite.

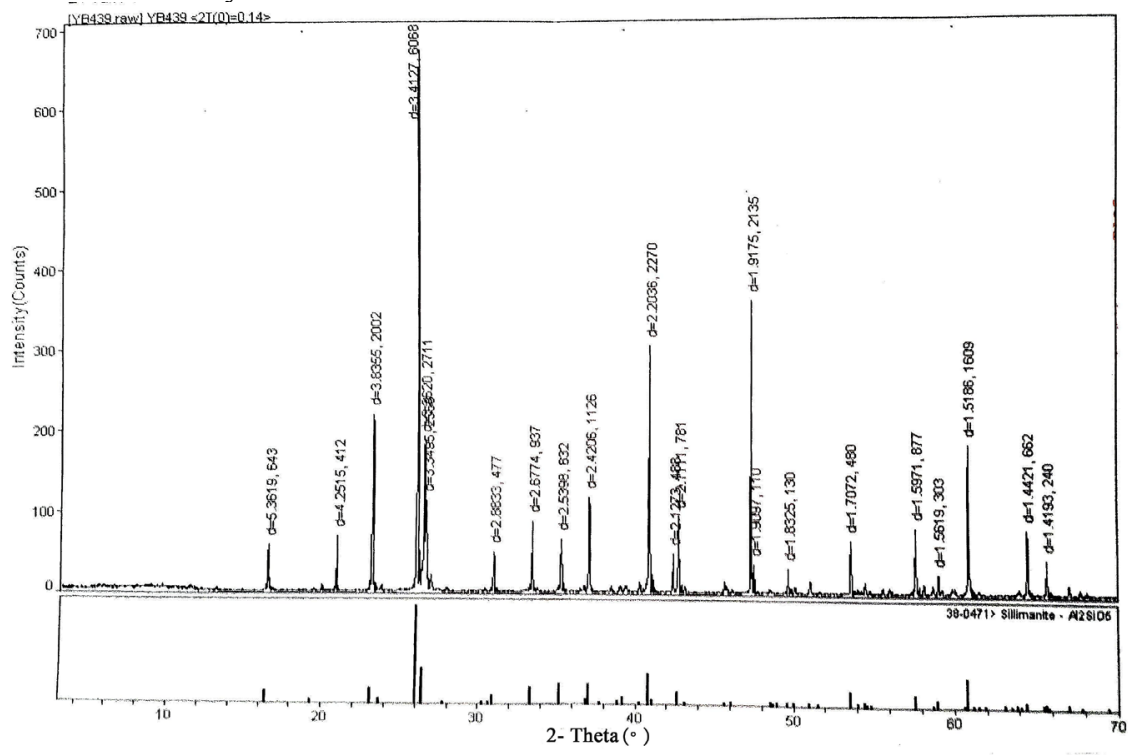

Fig. 1. The $\mathrm{X}$ ray diffraction petrographic analysis map of the composite silicate powder containing zirconium

Mullite has high refractoriness (stable at $1800^{\circ} \mathrm{C}$ ) and chemical inertness. The transformation process of from kyanite to mullite at high temperatures is irreversible, which is stable below $1810^{\circ} \mathrm{C}$. And when temperature decreases, the volume is stable and the shrinkage is low.

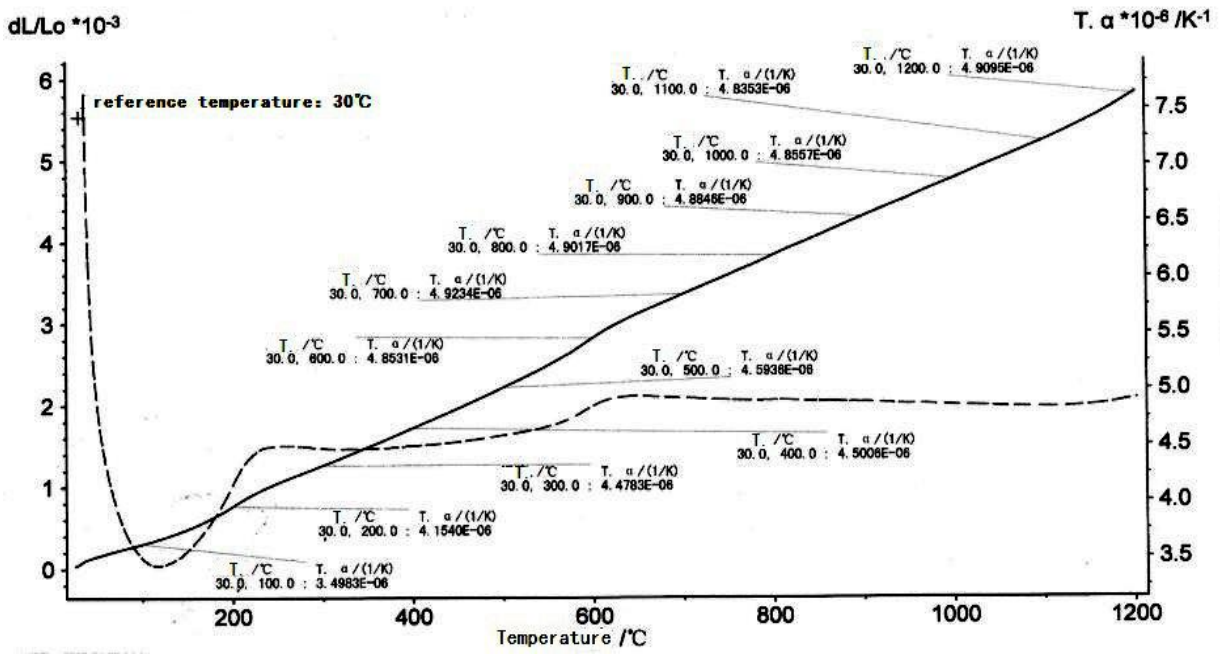

Fig. 2. The thermal expansion curve of the composite silicate powder containing zirconium

Fig. 2 shows the thermal expansion curve of the composite silicate powder containing zirconium. Kyanite increases the difference of the linear contraction coefficient between the composite silicate powder containing zirconium coating and casting metal, which produce 
greater shear stress between casting and coating boundary and can lead to self-stripping in layers between coating and casting. The cristobalite with high viscosity (glass polymer) in the process of transformation process of kyanite at high temperatures can resist the permeation of molten metal. It is helpful to prevent the mechanical burn-on defect of steel castings. And since the difference of the linear contraction coefficient between the glass coating layer and the casting metal is large after cooling, which increase shear stress between casting and coating boundary and further lead to self-stripping in layers between coating and casting, thereby obtaining castings with smooth surface. The thermochemistry stability of generated mullite is strong. The mullite is not easy to react with acid and alkaline oxides that are helpful to prevent the chemical burn-on defect of steel castings.

The price of the composite silicate powder containing zirconium is only $1 / 3 \sim 1 / 4$ that of zircon powder. But particle shape of the composite silicate powder containing zirconium is mainly polygonal (see Fig. 3), which is a little worse than that of spherical zircon powder (see Fig. 4).

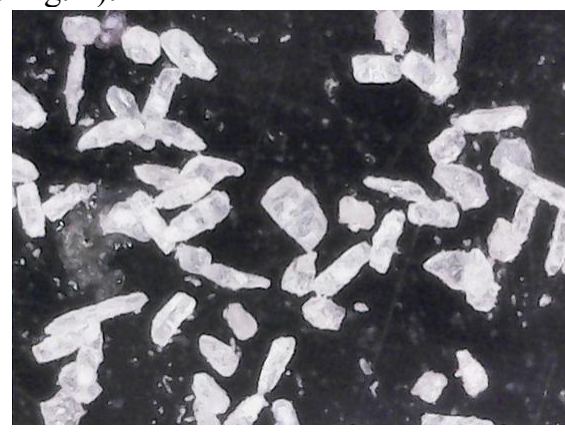

Fig. 3. The particle morphology of the silicate powder containing zirconium $(200 \times)$

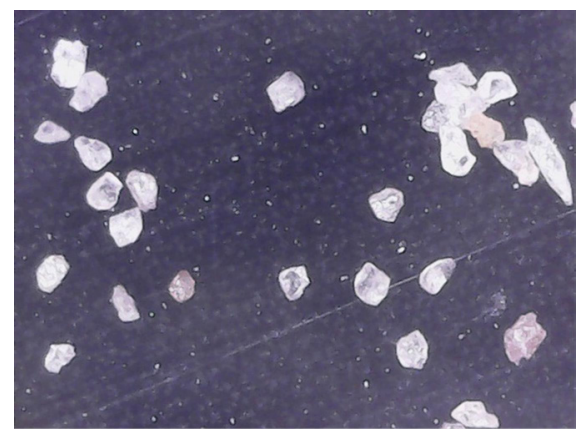

Fig. 4. The particle morphology of zircon composite powder $(200 \times)$

\subsection{Sintering agent}

The sintering agent should ensure that the sinter can form a continuous dense sinter skin, which has a significant ability to prevent burn-on and shield carbon. In this study, fluoride was selected as sintering agent.

The sintering mechanism of fluoride is that the electrostatic potential of F- introduced by fluoride is only about $1 / 2$ that of $\mathrm{O} 2-$, and the radius of both ions are very close. Freacts with aluminum-oxygen or silicon-oxygen network in refractory aggregate, which can break the network. The equation is as follows:<smiles></smiles>

The damage of $\mathrm{F}^{-}$to the network can reduce the melting temperature of refractory aggregate, but excessive fluoride can reduce its damage to the network. The experimental results show that the suitable dosage of fluoride is $1 \% \sim 3 \%$ amount of the refractory aggregate.

In addition, a sintering aid is adopted. It not only can promote the sintering of coating layers, but also can decompose at temperatures over $1000^{\circ} \mathrm{C}$, which can produce a reducing gas with good stability at elevated temperature and high vapor pressure. This reductive gas and sintered compact coating together can avoid contact of solid 
carbonaceous material in the sand mold (core) / casting interface with hot metal, and can prevent solid diffusion of carbon to layer of molten steel interface, thus effectively reduces or eliminate the surface carburization of castings.

\subsection{Particle size and gradation}

The smaller the radius of such powder material as the refractory aggregate and the sintering agent etc., the better the suspension property and brush ability, the greater the penetration depth of the coatings to the sand mold, the better the shielding effect of the coating on the carbon, the lower the adding amount of suspending agent needed. The finer the particle size of sintering agent, the easier the sintering of the coating, the higher the density, the better the shielding effect on carbon. But if the particle size of powder is too small, it will make the coating easily be cracked, and affect anti-metal-penetration and anti-carburizing ability. Therefore, the particle size of such powder material as the refractory aggregate and the sintering agent etc. should be moderate, which is appropriate between -200 and 500 meshes.

Refractory aggregate must also have a reasonable particle gradation, and the size distribution should show large dispersion within the appropriate particle size range to make full use of mutual mosaic effect of coarse and fine particles, reduce the inter particle porosity in order to obtain compact coatings, improve its anti-metal penetration and anticarbonization ability.

\subsection{Binder}

Foundry coating not only has a certain normal temperature strength, but also have good high temperature strength, so the binder should adopt a composite process using organic binder at low temperature together with inorganic binder at high temperature. However, the organic binder generally contains carbon, and its pyrolysis products are bound to contain carbon. Therefore, in order to ensure that the coating have a certain normal temperature strength, the adding amount of organic binder in coating should be minimized and a little more inorganic binder at high temperature should be used. The coating use normal temperature air-dried organic binder at low temperature together with inorganic binder at high temperature as binder [8].

\subsection{Solvent}

There are two kinds of commonly used solvents: water and alcohol. When alcohol is used as solvent, binder is generally organic binder. Since pyrolytic carbon produced by alcohol solvent and organic binder in the casting process remain in the coating, which will increase the tendency of carburizing of casting. Therefore, the coating uses water as solvent.

\section{Main properties of composite silicate powder anti-carburizing coating containing zirconium}

Tested by Guangdong province casting molding material engineering technology center, the main technical properties of new composite silicate power anti-carburizing material containing zirconium (water-based and air-dry) is shown in table 1. Brushing index in the table refers to the ratio of apparent viscosity $\eta 6$ at low shear rate $(6 \mathrm{r} / \mathrm{min})$ and $\eta 60$ at high shear rate $(60 \mathrm{r} / \mathrm{min})$, which characterizes shear thinning or thickening property of coatings. The higher the index, the better the brushing property of coating, which means easy operation of brushing, good anti-flowing property and easy thick coating. 
Thixotropy rate refers to the change rate of the apparent viscosity of coating $\eta$ with the change of stirring time. The higher the thixotropy rate, the better the leveling property, the greater the dilution range, the better the brushing property, the worse the anti-flowing property.

Table 1. Technical performance of composite silicate powder anti-carburizing coating containing zirconium.

\begin{tabular}{|c|c|c|c|c|c|c|c|}
\hline Solvent & $\begin{array}{c}\text { Conditional } \\
\text { viscosity } \\
\mathbf{s}\end{array}$ & $\begin{array}{c}\text { Density } \\
\mathbf{g} \cdot \mathbf{c m}^{-3}\end{array}$ & $\begin{array}{c}\text { Suspension } \\
\text { property(24h) } \\
\mathbf{\%}\end{array}$ & $\begin{array}{c}\text { Thixotropy } \\
\text { rate } \\
\mathbf{\%}\end{array}$ & $\begin{array}{c}\text { Brushing } \\
\text { index }\end{array}$ & $\begin{array}{c}\text { Gas } \\
\text { evolution } \\
\mathbf{m} \cdot \mathbf{g}^{-\mathbf{1}}\end{array}$ & $\begin{array}{c}\text { Hot } \\
\text { cracking } \\
\text { grade }\end{array}$ \\
\hline water & 12 & 1.92 & 99 & 37.2 & 7.6 & 12.7 & $\mathrm{I}$ \\
\hline
\end{tabular}

\section{Application effects of coatings on stainless steel castings}

The trial casting is stainless steel impeller, whose material grade is $\mathrm{ZG1Cr} 18 \mathrm{Ni}$ Ti. The casting weight is about $30 \mathrm{Kg}$, the wall thickness is $15 \mathrm{~mm} \sim 22 \mathrm{~mm}$ and the tapping temperature of molten steel is about $1700{ }^{\circ} \mathrm{C}$. Acid-cured furan resin self-hardening sand was used to make cores, at the same time, two identical rectangular specimen sand mold were manufactured, whose size is $50 \times 90 \times 110 \mathrm{~mm}$. Two kinds of casting sand mold and block sand were used to compare the water based self-drying coatings containing zirconium and silicate powder and coatings. Water-based and self-drying composite silicate powder coating containing zirconium and water-based and self-drying zircon powder coating were used separately in two casting sand mold and specimen sand mold for contrast. The total thickness of the coating is $0.5 \mathrm{~mm} \sim 0.8 \mathrm{~mm}$ and it doesn't need to be dried before casting, so as to avoid the influence of residual carbon produced by flame combustion on coating surface on surface carburization of castings.

A line cutting machine was used to intercept section specimen at the same position of the specimen, and chemical composition of the center and surface of direct reading spectrometer test block were used separately.

The experiment results show that the suspension property of the new anti-carburizing composite silicate powder alcohol based coating containing zirconium is good, is easy to brush and is good in levelling property. The coating of castings and blocks produced using the coating was basically automatically stripped from the casting surface flakily; no defects such as sand burning, porosity, sand inclusion, coating inclusion etc. were seen on the casting surface.

Table 2 shows the spectral analysis results of chemical composition of two kinds of specimen (comparison of two coatings) at different distances below the surface.

The original carbon content of molten steel is $0.106 \% \sim 0.110 \%$, and the carbon content of the surface layer of castings should be controlled within $0.12 \%$ after pouring.

It can be known from table 2 when using the new composite silicate powder anticarburizing coating containing zirconium that the carbon content of the surface of the test block is $0.136 \%$ and maximum carburizing rate is $23.6 \%$. The carbon content of the upper limit of $0.12 \%$ of the carburizing layer thickness is about $1 \mathrm{~mm}$, the anti-carburizing effect is significant. And when using a domestic zircon powder composite coating, the carbon content of the surface of the test block is up to $0.178 \%$, exceeding the allowable upper bound of carbon content $0.12 \%$, which does not reach the quality requirements of manufacturing. The highest carburizing rate is $67.9 \%$, about three times more than the new coating. The thickness of the carburized layer corresponding to the allowable upper limit of carbon content is more than $2 \mathrm{~mm}$. 
Table 2. Spectrum analysis results of chemical composition at different depth under the surface of stainless steel impeller casting specimen

\begin{tabular}{|c|c|c|}
\hline Types of coatings & position & $\mathbf{C} / \mathbf{\%}$ \\
\hline \multirow{3}{*}{$\begin{array}{c}\text { composite silicate powder coating } \\
\text { containing zirconium }\end{array}$} & Specimen surface & 0.136 \\
\cline { 2 - 3 } & Under specimen surface $1 \mathrm{~mm}$ & 0.122 \\
\cline { 2 - 3 } & Under specimen surface $2 \mathrm{~mm}$ & 0.115 \\
\cline { 2 - 3 } & Center of specimen & 0.110 \\
\hline \multirow{4}{*}{ zircon powder coating } & Specimen surface & 0.178 \\
\cline { 2 - 3 } & Under specimen surface $1 \mathrm{~mm}$ & 0.137 \\
\cline { 2 - 3 } & Under specimen surface $2 \mathrm{~mm}$ & 0.132 \\
\cline { 2 - 3 } & Center of specimen & 0.106 \\
\hline
\end{tabular}

Fig. 5 is the result of energy spectrum analysis of carbon content increment ratio, which is beneath the surface layer within $6 \mathrm{~mm}$ depth and two kinds of specimen, whose left and right sides are using a domestic zircon powder composite coating and the new composite silicate powder anti-carburizing coating containing zirconium, which is cast by the molten steel of the same furnace and is measured by Shimadzu Corporation EPMA-1720 energy spectrum analyser. The results show that it basically agrees with the results of using the spectrometer test, this further proved that the new coating has a good effect of anticarburizing.
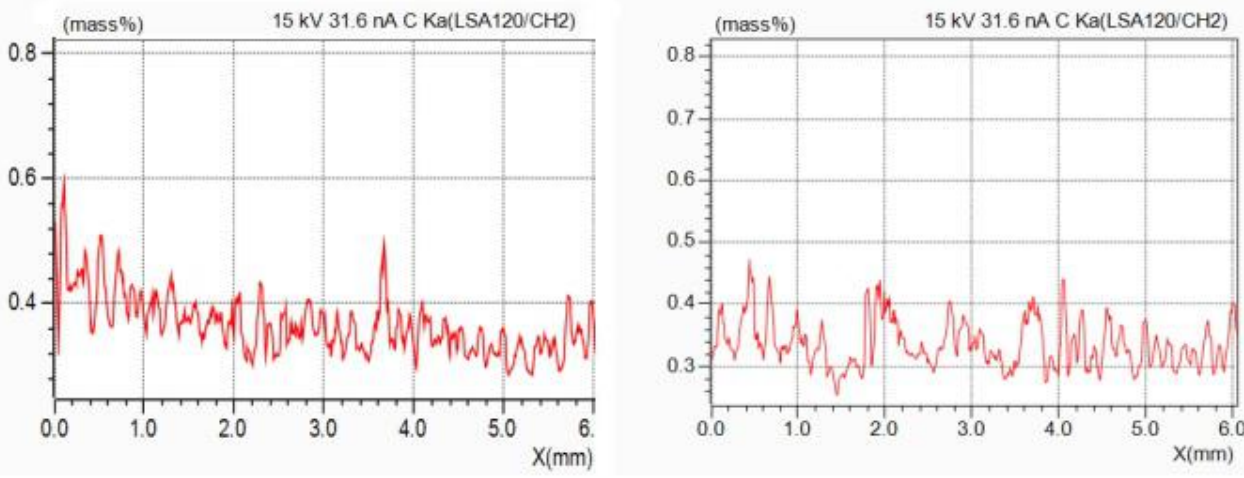

Fig. 5. The results of the spectrum analysis of the specimen surface (incremental ratio of carbon content (Left: Using zircon powder coating Right: Using composite silicate powder coating containing zirconium)

\section{The anti-carburizing and anti-metal penetration mechanism of composite silicate powder coating containing zirconium}

Scanning electron microscope (SEM) was used to observe the changes of the microstructure of the coating after casting and cooling. The results are shown in Fig. 6. 

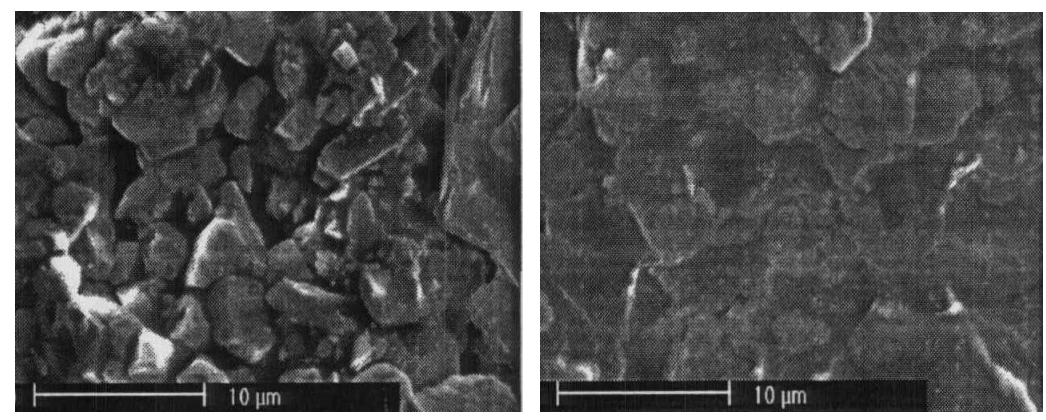

Fig.6. The SEM morphology of sinterskin surface of composite silicate powder coating containing zirconium (Left: Using zircon powder coating Right: Using composite silicate powder coating containing zirconium)

It can be seen from Fig. 6 that an irreversible phase change and great expansion occurs in the kyanite in the zircon powder coating at lower temperature compared with those in zircon powder coating. It makes the powder particle surface in the sinter-skin of coating sintered more fully. Common adhesion between particles occurs due to surface melting, the coating exist as glassy phase. The gap of the coating is small and the density of coating is high, which has a strong shielding effect on the migration and diffusion of elements. This is the reason why the silicate powder coating containing zirconium has good anti-carburizing and anti-metal penetration performance.

\section{Conclusions}

(1) The permeability, anti-flowing property and crack resistance of low carbon steel resin sand casting anti carburizing coating based on composite silicate powder containing zirconium are very good. The coating exhibits high strength and low gas evolution. Most of the coating can be stripped out flakily when the casting is shaken out, the casting surface is clean and the effect of anti-metal penetration is good. There are no defects such as porosity, sand inclusion, coating inclusion etc. The cleaning efficiency of casting is greatly improved, energy is saved and labor intensity is decreased.

(2) The thickness of the carburizing layer of composite silicate powder coating containing zirconium relative to the allowable limit of carbon content is about $1 \mathrm{~mm}$, whose maximum carburizing rate is $23.6 \%$. Anti-carburizing effect of the casting is significantly higher than that of zircon powder coating, whose maximum carburizing rate is $67.9 \%$ and the thickness of the carburizing layer relative to the allowable limit of carbon content is more than $2 \mathrm{~mm}$, which can basically meet the production demands of low-carbon steel castings such as stainless steel.

(3) The zirconium containing composite silicate powder coating can greatly reduce the cost of the coating and the cost of casting production, because it can greatly reduce the cost of the zirconium powder, which is of high cost and has a certain radioactivity. It also can improve foundry production environment and help to protect the health of workers.

In this paper, the research was sponsored by Industry-university-research Cooperation Projects of Zhuhai City, Guangdong Province, China (Project No. 2012D0501990013).

\section{References}

1. L. Li, R. Tan, H.K. Li, et al, Study on the Anti-Carburizing Coating Applied to Furan Resin Sand, Foundry. 63, 386(2014) 
2. L. Zhao, Y. Tian, Y.X. Wang, et al, Effect of Furan Resin Sand on Carburization Defects of Ultra-Low Carbon Steel Casting, Foundry. 63 , 929(2014)

3. T. Z. Li, Effect of Furan Resin Bonded Sand Mold on Surface Microstructure of Steel Castings, Foundry. 59, 1069(2010)

4. S.S. Feng, Investigation and Application of Carbon-impervious Coating on the Surface of Low-cabon Steel Castings, Foundry Technology. 31, 1551(2010)

5. Z. Zhang, M. Chen, Application of Shielding Coating to Steel Casting Process, Foundry. 59, 940(2010)

6. Z.Z. Wu, C.C. Yang, The Radioactivity of Zircon Sand and its Harmful to Human Bodies, Industrial Safety and Environmental Protection. 29, 20(2003)

7. S.Y. Wang, B.J. Zhangn,C.T. Du, et al, Study on DNA Damage Effect of Zircon Powder on Foundry Workers, Chinese Journal of New Clinical Medicine. 4, 563(2004)

8. C.Y. Zhan, S.S. Feng, S.Z. Xie, et al, Curing properties of water-based self-drying fastdrying foundry coating, Proceedings of the 2015 3rd international conference on material, mechanical and manufacturing engineering. 27, 1984(2015) 